\title{
The Relationship among Emotional Leadership, Coach Trust and Athletic Satisfaction of University Soccer Players
}

\author{
Sunghoon $\mathrm{Kim}^{1}$ and Jung Taek Shin ${ }^{2} *$ \\ ${ }^{1}$ Department of Physical Education, Yonsei University, Seoul, Korea \\ ${ }^{2}$ Department of Physical Education, Dongeui University, Busan, Korea
}

\begin{abstract}
[Purpose] The purpose of this study was to analyze the relationship among emotional leadership, coach trust and athletic satisfaction of university. [Methods] 288 university soccer players were surveyed on the emotional leadership questionnaire, coach trust questionnaire and athletic satisfaction questionnaire through convenience sampling method. SPSS 23.0 and AMOS 23.0 were used to achieve the purpose of this study. Frequency analysis, confirmation factor analysis, reliability verification, correlation analysis and the structural equation model analysis were performed. [Results] First, emotional leadership had a positive effect on coach trust of university soccer players. Second, emotional leadership had a positive effect on athletic satisfaction of university soccer players. Third, coach trust had a positive effect on athletic satisfaction of university soccer players. Finally, coach trust mediated the relationship between emotional leadership and athletic satisfaction. [Conclusions] Emotional leadership was a leadership that can efficiently increase coach trust, and leaders must communicate with players through emotional effort and team operations with goals of athletic satisfaction and happiness rather than wins and losses were required.
\end{abstract}

Key words: emotional leadership, coach trust, athletic satisfaction, mediation effect, university soccer players

\section{서 론}

\section{1. 연구의 필요성}

2020년 U리그 5권역에서는 전주기전대학이 우승을 차 지하였다. 대학리그에서 전문대학이 권역 우승은 이번이 처 음 있는 일로 지도자와 선수들이 하나가 되어 일궈 낸 성과 이다. 또한, 전문대학교인 송호대학교는 2016년 U리그 왕 중왕전 준우승, 안동과학대학교는 2016년, 2019년 1, 2학 년 대학축구대회에서 우승하여 대학축구리그에서 전문대학 의 가능성과 희망을 보여주었다.

논문 투고일 : 2021.03.02.

논문 수정일 : 2021.04.19.

게재 확정일 : 2021.05.13.

* 교신저자 : 신정택(sjt@deu.ac.kr)
대학축구 리그에서의 전문대학들은 얇은 선수층과 전문 대 특성상 졸업이 빠르기 때문에 제대로 된 실력을 발휘하는 데 한계가 있어서 안정된 경기력과 성적을 유지하는데 어려 움이 많다. 하지만 열악한 환경 속에서도 선수들을 다독이 며, 선수들과 함께 훈련해 온 지도자들의 리더십이 좋은 성 과를 이뤄내는데 큰 역할을 하였다. 또한, 대학선수들은 성 인으로서의 성숙된 모습으로 보다 많은 열정과 각자의 개성 적인 사고방식으로 생활하기 때문에, 대학축구 지도자들은 선수를 이해하고 공감하며, 선수들의 감성을 고려한 프로그 램 적용으로 훈련의 성과를 높이고 있다. 이처럼 대학축구 선수들을 이해하고 공감하는 능력은 리더십을 극대화하는 데 도움을 주며, 어려운 환경 속에서 리더십을 통한 우수한 경기력 발휘는 좋은 본보기로서 활용될 필요성이 있다. 리더십은 집단의 목표를 달성하기 위해 구성원들에게 행 
사하는 영향력으로 정의할 수 있으며, 특성, 행동 및 상황의 관점에 따라 변화되어 왔다(Luthans, 2002; Stajkovic, 2006).

스포츠에서 지도자들의 리더십은 선수들의 성장과 목표 달성, 팀의 경기 승·패에 매우 중요한 요인이라 할 수 있다 (Ha \& Kim, 2017). 특히, 지도자 스스로 자신을 이해하고 선수들의 감성과 욕구를 이해하며, 상호작용을 통해 긍정적 인 방향으로 이끌어 가는 감성리더십이 주목 받고 있다.

감성리더십의 연구는 Salovey \& Mayer(1990)의 연구에 서 시작되었으며, 리더가 구성원들의 감정을 인식하여 관리 및 공감을 통해 긍정적 관계를 형성하여 조직에 영향력을 행 사하는 행위로 정의 하였다(Mayer, DiPaolo, \& Salovey, 1990). 이러한 감성리더십의 연구는 Goleman(1995)의 '감성지능(Emotional Inteligence)'이라는 책이 출간 된 이후 감성리더십에 대한 연구가 본격화되었으며, 업무성과 의 성공요인은 지능 요인(IQ)이 $20 \%$, 감성지능 요인(EQ)이 $80 \%$ 를 차지하여 업무 성과의 성공을 위해서는 지능지수보 다는 감성지능이 더 크게 좌우된다고 하였다.

Goleman, Boyatzis \& Mckee(2002)는 효율적인 리더 십을 발휘하기 위해서는 구성원들의 감성을 잘 활용해야하 며, 진정한 리더가 되기 위해서는 우선적으로 감성 지능을 갖 춰야 한다고 주장하였다(Goleman, et al, 2002). 감성리더 십의 구성개념은 관계관리, 지각능력, 감정관리, 사교능력 4 가지로 구분된다. 관계관리는 의사소통을 통해 정보나 내용 을 상호교환하며, 공감대를 형성하고 서로의 지각, 사고 감동 등의 변화를 이뤼내는 과정이며(Crino \& White, 1981), 지 각능력은 리더가 구성원들에게 어떻게 평가되고 있는지를 인 식하는 것으로 성공적인 리더가 되기 위한 중요한 요인이다 (Crossan, Vera, \& Nanjad, 2008; Taylor, 2010). 감정관 리는 개인의 감정을 인지적으로 활용할 수 있도록 감성과 이 성을 통합하여 관리하는 능력이며(Yukl, 2002), 사교능력은 사회적 요구를 받아들여, 구성원들과 협의를 통한 공감적 해 석으로 사회적 요구에 대해 효율적으로 대응하는 행동이다

(Witt \& Ferris, 2003; Wu \& Turban, 2009).

감성리더십의 4 가지의 구성개념을 잘 숙지하여 감성능 력을 향상시키는 일은 리더로서 성공하는데 결정적인 역할 을 한다(Wall, 2007). 스포츠 상황에서의 지도자들이 급진 적이고 변혁적인 방법으로 팀의 변화를 주더라도, 결국 미 래에 지도자로서 얼마나 성공할 것인가를 결정하는 것은 감 성능력이며, 지도자로서 성공을 위해서는 선수와의 상호작
용에 관심을 가지고 신뢰와 열린 대화를 통해 선수를 이해하 고 공감하는데 주력해야 할 것이다.

스포츠 상황에서 감성리더십 선행연구를 살펴보면, 내적 동기와 선수만족(Ha \& $\mathrm{Kim}, 2017)$, 지도자 신뢰와 지도자 -선수 교환관계(Kim \& Back, 2016), 지도자-선수 관계와 운동의욕(Choi, Jeon, \& Jung, 2017), 탈진과 운동포기 (Kim \& Lee, 2019)), 자아존중감과 운동지속(Park \& Jung, 2020), 집단응집력(Do \& YOU, 2020), 임파워먼트 와 자기관리행동(Cho, Park, \& Kim, 2018) 연구에서 감 성리더십과의 관련성이 높은 것으로 나타났다. 이러한 연구 들은 스포츠 상황에서의 감성리더십의 효과성을 입증하는 결과라 할 수 있으며, 전문대 축구지도자들의 우수한 경기 성과와 리더십은 높이 평가 받아야 하며, 축구지도자들의 긍정적인 리더십 변화에 큰 도움이 될 것이다.

한편, Bennis(1995)에 의하면, 성공한 리더들의 능력 중 신뢰 관리 능력의 중요성에 대해서 언급하였으며, 이러한 신뢰 관리 능력은 리더와 구성원과의 믿음을 형성하기 위한 노력으로 구성원의 관계, 조직 문화와 환경요인의 개선 등 의 노력을 통해 신뢰 관계를 향상시켜야 된다고 하였다. 지 도자 신뢰는 리더의 가치관에 대한 구성원들의 확신과 믿 음, 호의적인 태도에 대한 긍정적인 감정 상태라고 정의하 였으며(Johnson \& Swap, 1982), 지도자를 믿고 의지하려 는 구성원들의 심리적인 감정 상태라고 할 수 있다. 이러한 지도자 신뢰의 중요성은 3 가지로, 첫째 조직의 높은 성과를 달성하도록 촉진하며(Boss, 1978), 둘째, 조직 및 개인의 장기적인 안정성을 제공하고(Cook \& Wall, 1980) 셋째, 구성원들이 공동체 의식 및 조직의 일체감을 갖고 자율적이 고 능동적인 참여를 돕는다(Degoey \& Tyler, 1996).

스포츠 상황에서는 축구와 같은 팀 스포츠의 경우 팀의 목표를 달성하기 위해서는 지도자 신뢰가 매우 중요하다. 특히, 선수들의 특성 파악, 팀 전술 및 전략을 이끄는 지도자 신뢰는 경기의 승-패를 결정짓는 주요 변인이며, 2002 월드 컵의 히딩크 감독, 2012 런던 올림픽의 홍명보 감독, 베트 남의 영웅 박항서 감독과 같은 지도자들이 축구 현장에서 신 뢰와 소통을 왜 중요시 여기는지 알 수 있다.

결국, 리더십과 지도자 신뢰는 깊은 관련성이 있으며, 지 도자 신뢰 선행연구를 살펴보면, 감성 리더십 $(\mathrm{Kim} \&$ Back, 2016), 대응가치리더십(Kim, Wang, \& Kim, 2016), 윤리적 리더십(Kim \& Kim, 2020), 카리스마 리더 십(Lee \& Cho, 2009) 등의 연구에서 리더십과 지도자 신 
뢰는 밀접한 관련성이 있는 것으로 나타났다.

또한, 지도자 신뢰는 리더십과 다양한 변인들과의 매개 효과가 있는 것으로 나타났으며, 자도자 유형과 운동지속의 도간의 매개효과(Lee \& Jun, 2016), 리더십과 운동 몰입간 의 매개효과(Yoon, 2014), 지도자 유형과 지도효율성과의 매개효과(Choi, Won, \& Lee, 2006) 등의 연구들이 스포 츠 상황에서 지도자들의 리더십에 영향을 받은 지도자 신뢰 가 다양한 심리변인들에게 영향을 주는 것으로 나타나, 지 도자 신뢰의 중요성을 확인할 수 있다.

선수만족은 대학축구선수들이 선수생활을 수행하는 동 안 얻게 되는 다양한 경험과 수행의 결과를 평가하여 느끼는 개인 정서상태에서 오는 긍정적인 심리상태를 의미하며 (Lee \& Oh, 2012), 선수들이 지각하는 지도자 리더십, 동 료 관계, 훈련 수행 과정, 훈련 성과 등에서의 심리적 만족감 으로 이해할 수 있다(Ha, 2020). 특히, 지도자 리더십은 선 수만족에 직접적인 영향을 미치는 것으로 선행연구들(Kim, 2014; You, 2020; Ha \& Kim, 2017)에서 규명되었으며, Kang \& Oh(2015)과 Lee(2011)의 연구에 따르면, 지도자 신뢰가 높을수록 선수 만족도 높은 것으로 나타나, 지도자 신뢰는 선수 만족의 선행변인이라는 것을 확인하였다.

종합하면, 감성적 리더십, 지도자 신뢰, 선수만족 간의 관 련성이 높은 것을 알 수 있다. 이러한 관련성은 전문대 축구 지도자들이 우수한 성과를 낼 수 있었던 코칭의 근거를 제시 하고 있다. 선수들을 이해하고 공감하며 소통하는 감성적 리더십은 선수들로 하여금 지도자를 신뢰하고 믿을 수 있도 록 하는 역할을 하여 긍정적인 성과를 높이는데 도움을 준 다. 하지만, 선행연구에서는 대학축구선수를 대상으로 하는 감성적 리더십에 대한 연구가 전무한 실정이다. 대학선수들 은 자신만의 욕구와 성향을 명확히 표현하는 시기이므로, 감성적 리더십의 발휘가 선수들에게 어떠한 영향을 미칠 수 있는지에 대한 연구를 통해서 대학축구선수들의 경기력 향 상에 도움을 주고자 이 연구를 진행하게 되었다.

특히나, 대학축구선수들은 축구를 시작해서 대학선수가 되기까지, 지도자들의 전략과 전술을 믿고 순응하며, 경기 에 참여해 왔다. 하지만, 지도자에 대한 자신의 주관적인 측 면이 강하게 나타나는 시기이므로, 지도자가 발휘하는 리더 십에 따라 신뢰의 차이는 달라질 수 있을 것으로 예상되며, 이러한 지도지 신뢰의 매개효과를 분석하는 것은 큰 의미가 있을 것으로 판단된다.

이에 본 연구의 목적은 리더의 자신을 알고, 구성원들의
감정을 이해 및 공감하며 긍정적인 관계를 형성하여 조직에 영향력을 행사하는 감성리더십과 지도자 신뢰 및 선수 만족 의 구조적 관계를 규명함으로써 대학축구에서 지도자의 역 할의 중요성과 효율적인 스포츠 리더십 연구에 기초자료를 제공하는 것이다.

\section{2. 연구 가설}

본 연구에서 설정한 목적을 규명하기 위해 다음과 같은 연구가설을 설정하였다. 첫째, 대학 축구선수들의 감성리더 십은 지도자 신뢰에 영향을 미칠 것이다. 둘째, 대학 축구선 수들의 감성리더십은 선수 만족에 영향을 미칠 것이다. 셋 째, 대학 축구선수들의 지도자 신뢰는 선수 만족에 영향을 미칠 것이다. 넷째, 대학 축구선수들의 감성리더십과 선수 만족 관계에서 지도자 신뢰는 매개 효과가 있을 것이다.

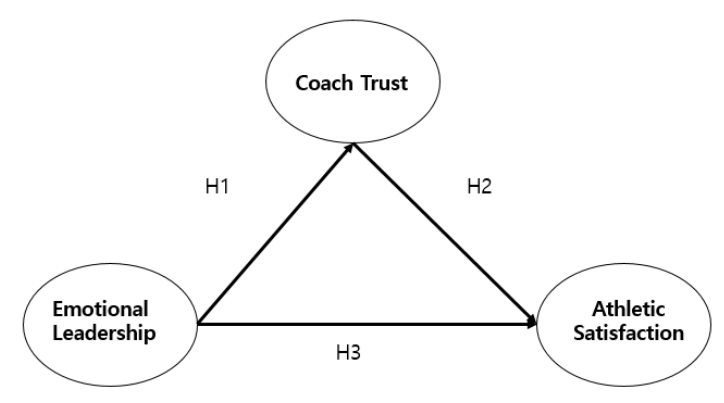

Fig. 1. A hypothesized model

\section{연구방법}

\section{1. 연구대상}

본 연구의 대상은 경기·광주·전남지역에 있는 남자대학 축구선수 300 명을 대상으로 편의표본 추출을 통해 설문하 였으며, 이 중 무응답 설문 11 부를 제외한 288 부를 바탕으 로 연구절차에 따라 분석하였다. 설문기간은 2020년 12월 1 일부터 12 월 15 일까지 15 일간 설문조사를 실시하였으며, 코로나 방역 차원에서 학교와 지도자들의 협조를 받아, 선 수들의 이메일을 통해 개별 설문을 실시하고 회수하였다. 인구통계학적 변인은 〈Table 1)과 같다. 
Table 1. The demographic characteristic of participants

\begin{tabular}{cccc}
\hline \hline \multirow{2}{*}{ Variable } & $\mathrm{N}$ & $\%$ \\
\hline \multirow{4}{*}{ Grade } & 1 & 95 & 33.0 \\
& 2 & 80 & 27.8 \\
& 3 & 66 & 22.9 \\
\multirow{3}{*}{ Position } & Defender & 146 & 16.3 \\
\hline \multirow{4}{*}{} & Midfielder & 90 & 50.7 \\
& Striker & 37 & 31.3 \\
& Goalkeeper & 15 & 12.8 \\
\hline \hline
\end{tabular}

\section{2. 조사도구의 타당도와 신뢰도}

본 연구에서는 측정도구의 타당도와 신뢰도를 높이기 위 해 전문가 집단(스포츠심리학 전공 교수 1 명, 측정 평가 전 공 교수 1 명, 스포츠 심리학전공 박사 1 명)을 구성하여 측정 도구에 대한 내용타당도를 검증하였으며, 설문을 통해 확인 적 요인분석(Confirmatory factor analysis)과 신뢰도 분 석(Cronbach's $\alpha$ )을 실시하였다.

\section{1) 감성리더십}

감성리더십의 측정도구는 $\mathrm{Ha} \& \mathrm{Kim}(2017)$ 의 연구에서 활용한 18 개 문항을 대학 축구선수들에게 맞게 수정·보완하 여 구성하였다. 지도자의 자기인식(Self Awareness) 3문항, 자기관리(Self Management) 6문항, 사회적 인식(Social Perception) 3문항, 관계관리(Relationship Management) 6문항, 4 요인 18 문항으로 구성하였다. 본 척도의 확인적 요 인분석 결과, $\mathrm{SMC}$ (Squared Multiple Correlations)가 낮 게 나타난 문항 3 문항(자기관리 1 문항, 관계관리 2문항)을 삭 제하였다. Q값은 6.781, TLI값은 .928 CFI값은 .912, RMSEA 값은 .075로 나타나, 4요인 15문항의 적합성을 확인 하였으며, 신뢰도분석 결과 Cronbach's $\alpha$ 값은 .87 .90으 로 나타나 신뢰도가 확보되었다.

\section{2) 지도자 신뢰}

지도자 신뢰의 측정도구는 Jeon(2016)이 개발한 지도자
신뢰 척도를 활용하였다. 지도자 신뢰는 능력(Ability) 6문 항, 배려(Benevolence) 6문항, 진실성(Integrity) 6문항, 열의(Diligence) 3문항으로 4요인 21문항이며, 5점 리커 트 척도로 구성되었다. 확인적 요인분석 결과, $\mathrm{SMC}$ (Squared Multiple Correlations)가 낮게 나타난 5문항 (능력 1문항, 배려 2문항, 진실성 2문항)을 삭제하였다. Q 값은 4.017, TLI값은 .938 CFI값은 .941, RMSEA값은 .065로 나타나, 4요인 16문항의 적합성을 확인하였으며, 신뢰도분석 결과 Cronbach's $\alpha$ 값은 .88 .91로 나타나 신뢰도가 확보되었다.

\section{3) 선수 만족}

선수 만족의 측정도구는 $\mathrm{Ha} \& \operatorname{Kim}(2017)$ 의 연구에서 활용한 12 개 문항을 대학 축구선수들에게 맞게 수정·보완 하여 구성하였다. 운동 만족(Exercise Satisfaction) 5문 항, 환경 만족(Environment Satisfaction) 5 문항, 사회적 승인 만족(Social Approval Satisfaction) 2문항의 3요인 12 문항으로 구성하였다. 확인적 요인분석 결과, SMC (Squared Multiple Correlations)가 낮게 나타난 문항 4 문항(운동 만족, 2문항, 환경 만족 2문항)을 삭제하였다. Q 값은 4.587, TLI값은 .920 CFI값은 .925, RMSEA 값은 .074로 나타나, 3요인 8문항의 적합성을 확인하였으며, 신 뢰도 분석 결과 Cronbach's $\alpha$ 값은 .87 .90로 나타나 신 뢰도가 확보되었다.

\section{3. 자료처리 방법}

본 연구의 자료처리는 PASW 23.0과 AMOS 23.0 프로그 램을 활용하여 연구의 목적에 따라 분석을 실시하였다. 측정 도구와 신뢰도를 검증하기 위해 확인적 요인분석 (Confirmatory factor analysis)과 신뢰도 분석 (Cronbach's $\alpha$ )을 실시하였으며, 인구통계학적 변인들을 설정하여 빈도분석(Frequency analysis)을 실시하였다. 정 규분포 가정 여부를 확인하기 위해 기술통계(평균, 표준편 차, 왜도, 첨도)를 실시하고, 전체 측정모형의 구성타당도를 확인하기 위해 평균분산추출지수(AVE: Average Variance Extracted), 개념신뢰도(CR: Construct Reliability)를 분 석하였다. 판별타당도를 분석하기 위해 결정계수(r2: 상관계 수의 제곱)와 AVE 값을 비교하였으며, 관계분석을 위해 구 조방정식 모형(Structural Equation Model, SEM)을 검증 
하였다. 지도자 신뢰의 매개효과 분석을 위해 부트스트래핑 (Bootstrapping method)을 활용하였다.

\section{연구결과}

\section{1 , 기술통계분석}

대학 축구선수들의 감성리더십, 지도자신뢰, 선수만족의 기술통계분석은 〈Table 2〉와 같다. 각 측정변인들의 평균 은 3.35에서 4.13으로 나타났으며, 표준편차는 .43에서 .87로 나타났다. 정규성 검증을 위해 첨도와 왜도 값을 살펴 본 결과, 왜도는 -.212에서 .355로 나타났으며, 첨도는 -.263에서.355로 나타났다. \pm 2 를 넘지 않아 정규성을 만 족하는 것으로 나타났다.

Table 2. Result of the descriptive statistics analysis

\begin{tabular}{ccccc}
\hline \hline & $M$ & $S D$ & 첨도 & 왜도 \\
\hline Self Awareness & 3.35 & .43 & .355 & .228 \\
\hline Self Management & 3.72 & .69 & -.192 & .071 \\
\hline Social Perception & 3.89 & .79 & .264 & .095 \\
\hline $\begin{array}{c}\text { Relationship } \\
\text { Management }\end{array}$ & 3.60 & .79 & -.157 & -.132 \\
\hline Ability & 3.96 & .78 & .602 & .212 \\
\hline Benevolence & 4.01 & .87 & -.263 & -.212 \\
\hline Integrity & 3.88 & .62 & .686 & .004 \\
\hline Diligence & 3.68 & .83 & .192 & .355 \\
\hline $\begin{array}{c}\text { Exisercise } \\
\text { Satisfaction }\end{array}$ & 4.13 & .58 & .863 & .263 \\
\hline \hline $\begin{array}{c}\text { Environment } \\
\text { Satisfaction }\end{array}$ & 3.91 & .64 & -.418 & -.138 \\
\hline \hline
\end{tabular}

Table 3. Factor loading $(\lambda), \mathrm{CR}$, and AVE values of measurement model

\begin{tabular}{|c|c|c|c|c|c|}
\hline & Factors & & $\lambda$ & $\mathrm{CR}$ & AVE \\
\hline \multirow{15}{*}{$\begin{array}{l}\text { Emotional } \\
\text { Leadership }\end{array}$} & \multirow{3}{*}{$\begin{array}{c}\text { Self } \\
\text { Awareness }\end{array}$} & Q1 & .765 & \multirow{15}{*}{.920} & \multirow{15}{*}{.538} \\
\hline & & Q2 & .812 & & \\
\hline & & Q3 & .695 & & \\
\hline & \multirow{5}{*}{$\begin{array}{c}\text { Self } \\
\text { Management }\end{array}$} & Q4 & .674 & & \\
\hline & & Q6 & .715 & & \\
\hline & & Q7 & .650 & & \\
\hline & & Q8 & .814 & & \\
\hline & & Q9 & .754 & & \\
\hline & \multirow{3}{*}{$\begin{array}{c}\text { Social } \\
\text { Perception }\end{array}$} & Q10 & .621 & & \\
\hline & & Q11 & .809 & & \\
\hline & & Q12 & .756 & & \\
\hline & \multirow{4}{*}{$\begin{array}{l}\text { Relationship } \\
\text { Management }\end{array}$} & Q14 & .724 & & \\
\hline & & Q15 & .624 & & \\
\hline & & Q16 & .733 & & \\
\hline & & Q18 & .698 & & \\
\hline \multirow{16}{*}{$\begin{array}{l}\text { Coach } \\
\text { Trust }\end{array}$} & \multirow{5}{*}{ Ability } & Q1 & .854 & \multirow{16}{*}{.915} & \multirow{16}{*}{.520} \\
\hline & & Q2 & .756 & & \\
\hline & & Q3 & .723 & & \\
\hline & & Q4 & .698 & & \\
\hline & & Q5 & .657 & & \\
\hline & & Q7 & .749 & & \\
\hline & Donoulampo & Q8 & .672 & & \\
\hline & Benevolence & Q11 & .691 & & \\
\hline & & Q12 & .633 & & \\
\hline & \multirow{4}{*}{ Integrity } & Q15 & .756 & & \\
\hline & & Q16 & .783 & & \\
\hline & & Q17 & .865 & & \\
\hline & & Q18 & .811 & & \\
\hline & \multirow{3}{*}{ Diligence } & Q19 & .754 & & \\
\hline & & Q20 & .681 & & \\
\hline & & Q21 & .769 & & \\
\hline \multirow{8}{*}{$\begin{array}{c}\text { Athletic } \\
\text { Satisfaction }\end{array}$} & \multirow{3}{*}{$\begin{array}{c}\text { Exercise } \\
\text { Satisfaction }\end{array}$} & Q1 & .811 & \multirow{8}{*}{.929} & \multirow{8}{*}{.623} \\
\hline & & Q3 & .766 & & \\
\hline & & Q5 & .789 & & \\
\hline & \multirow{3}{*}{$\begin{array}{l}\text { Environment } \\
\text { Satisfaction }\end{array}$} & Q6 & .699 & & \\
\hline & & Q8 & .759 & & \\
\hline & & Q10 & .837 & & \\
\hline & \multirow{2}{*}{$\begin{array}{c}\text { Social } \\
\text { Approval }\end{array}$} & Q11 & .846 & & \\
\hline & & Q12 & .799 & & \\
\hline
\end{tabular}




\section{2. 측정모형 평가}

전체 측정모형의 구성타당도를 검증하기 위해 확인적 요 인분석을 실시하였으며, Q값은 3.417, TLI값은 .908, CFI 값은 .917, RMSEA 값은 .071로 양호한 것으로 나타났다. 집중타당도를 분석하기 위해 평균분산추출지수(AVE: Average Variance Extracted), 개념신뢰도(CR: Construct Reliability)를 분석하였으며, CR값은 .915에서 .929로 나타났으며, AVE 값은 .520에서 .653으로 나타나, 집중타당도가 있는 것으로 나타났다(CR >. 70, AVE >.50). 판별타당도를 분석하기 위해 AVE값과 결정계수(r2: 상관계 수의 제곱)와 비교한 결과, $\mathrm{AVE}$ 값이 큰 것으로 나타나 판별 타당도가 있는 것으로 나타나, 구성타당도를 확인하였다 〈Table 4〉. 각 변인의 표준화 계수, CR값과 AVE값은 $\langle$ Table 3〉과 같다.

\section{3. 연구모형 검증}

구조모형 분석의 각 변인 간의 경로계수를 살펴보면, 〈Fig.

Table 4. Values of correlation squared root and AVE among all factors of measurement model

\begin{tabular}{cccccc}
\hline \hline & & \multicolumn{4}{c}{$\mathrm{r}^{2}$} \\
\cline { 4 - 6 } Factors & CR & AVE & $\begin{array}{c}\text { Emotional } \\
\text { Leadership }\end{array}$ & $\begin{array}{c}\text { Coach } \\
\text { Trust }\end{array}$ & $\begin{array}{c}\text { Athletic } \\
\text { Satisfaction }\end{array}$ \\
\hline $\begin{array}{c}\text { Emotional } \\
\text { Leadership }\end{array}$ & .920 & .538 & 1 & & \\
\hline $\begin{array}{c}\text { Coach } \\
\text { Trust }\end{array}$ & .915 & .520 & .490 & 1 & \\
\hline $\begin{array}{c}\text { Athletic } \\
\text { Satisfaction }\end{array}$ & .929 & .623 & .350 & .333 & 1 \\
\hline \hline
\end{tabular}

2〉와 같다. 연구모형의 적합도와 경로계수는 〈Table 5〉, 〈Table 6>과 같다. 연구모형의 적합도는 $\mathrm{Q}$ 값은 2.225, RMSEA 값은 .065, TLI 값은 .940, CFI 값은 .955로 나타나, 모형의 적합성을 확인하였다. 구조모형분석의 결과를 바탕으 로 연구 가설의 검증을 하면 다음과 같다. 첫째, "감성리더십 은 지도자 신뢰에 유의한 영향을 미칠 것이다."는 경로계수 .279(t=3.847, p<.001)로 감성리더십은 지도자 신뢰에 통계 적으로 유의한 정적관계가 있는 것으로 나타났다. 둘째, "감 성리더십은 선수 만족에 유의한 영향을 미칠 것이다."는 경로 계수 .277(t=3.416, p<.001)으로 감성리더십은 선수 만족에 통계적으로 유의한 정적관계가 있는 것으로 나타났다. 셋째, "지도자신뢰는 선수만족에 유의한 영향을 미칠 것이다."는 경 로계수 .204(t=2.537, p〈.01)로 지도자 신뢰는 선수 만족에 통계적으로 유의한 정적관계가 있는 것으로 나타났다.

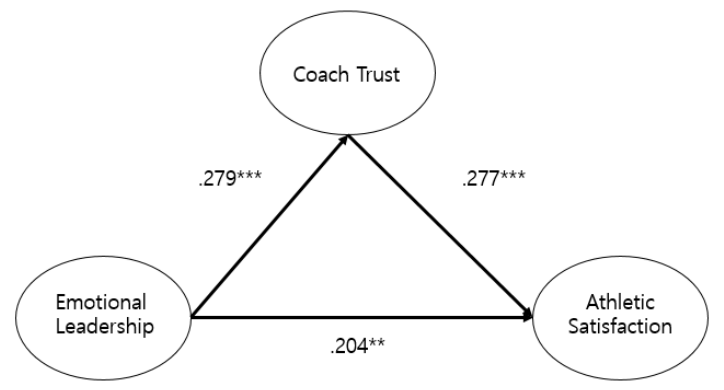

Fig. 2. Standardized coefficients of the structural equation model $(* * * p<0.001)$

Table 5. Fit index of research model

\begin{tabular}{cccccc}
\hline \hline $\mathrm{X}^{2}$ & $\mathrm{DF}$ & $\mathrm{Q}$ & RMSEA & TLI & CFI \\
\hline 91.216 & 41 & 2.225 & .065 & .940 & .955 \\
\hline \hline
\end{tabular}

Table 6. Hypothesis testing result and mediation effect result

\begin{tabular}{ccccccccc}
\hline \hline $\mathrm{H}$ & & Path & & $\beta$ & $\mathrm{t}$ & Direct effect & Indirect effect & Total effect \\
\hline $\mathrm{H} 1$ & Emotional Leadership & $\Rightarrow \Rightarrow$ & Coach Trust & $.288(.279)$ & $3.847^{* * *}$ & $.279^{* * *}$ & .000 & .279 \\
\hline $\mathrm{H} 2$ & Emotional Leadership & $\Rightarrow \Rightarrow$ & Athletic Satisfaction & $.200(.277)$ & $3.416^{* * *}$ & $.277^{* * *}$ & $.057^{*}$ & .334 \\
\hline $\mathrm{H} 3$ & Coach Trust & $\Rightarrow \Rightarrow$ & Athletic Satisfaction & $.142(.204)$ & $2.537^{* *}$ & $.204^{* *}$ & .000 & .204 \\
\hline \hline
\end{tabular}

Numbers in parenthesis are standardized coefficient. ${ }^{\mathrm{p}<.05,}{ }^{* *} \mathrm{p}<.01, * * * \mathrm{p}<.001$ 


\section{4. 매개효과 분석}

넷째, "대학 축구선수들의 감성리더십과 선수 만족 관계 에서 지도자 신뢰는 매개 효과가 있을 것이다." 라는 가설을 검정하기 위해 매개효과를 분석하였다.

매개효과는 Bootstrapping기법을 활용하였다. 반복 추 정 횟수는 2,000번으로 설정하고 $95 \%$ 신뢰구간에 의해 검 정하였다. 검정 결과, 최저구간(.011)과 최고구간(.118) 사 이에 0을 포함하지 않기 때문에 유의수준 $\mathrm{p}<.05(\alpha=.016)$ 에 서 통계적으로 유의한 것으로 나타나 매개효과가 있는 것으 로 나타났다.

\section{논 의}

본 연구는 리더의 자신을 알고, 구성원들의 감정을 이해 및 공감하며 긍정적인 관계를 형성하여 조직에 영향력을 행사하 는 감성리더십과 지도자 신뢰 및 선수 만족의 관계를 규명하 여 대학축구에서 지도자의 역할의 중요성과 효율적인 스포츠 리더십 연구에 기초자료를 제공하기 위함이다. 본 연구결과 를 바탕으로 논의하면 다음과 같다.

첫째, 감성리더십은 지도자 신뢰에 정적인 인과관계가 있는 것으로 나타났다. 이는 대학축구 지도자들의 감성리더십이 높 을수록 지도자 신뢰가 높아짐을 의미하는 것으로 이러한 결과 는 감성리더십은 리더와 구성원간의 의사소통, 신뢰 관계, 팀 워크 및 충성심 등에 영향을 미치며, 구성원들의 사기 및 업무 성과와도 높은 관련성이 있다는 선행연구들(Cooper \& Stwaf, 1997; Cherniss \& Adler, 2000; Dulewicz \& Higgs, 2003)이 본 연구를 지지해주고 있다. 또한, Dirks와 Ferrin (2002)의 상사신뢰에 관한 메타분석 연구에서 감성리더십이 조직신뢰에 긍정적인 영향을 미친다는 연구가 본 연구와 부분 적으로 일치하며, George(2000)는 리더는 구성원들의 긍정적 인 감정을 촉진시켜 올바른 방향으로 감정을 관리 및 활용 할수 록 팀 내 협력과 신뢰를 구축하는데 도움을 준다고 하여 본 연 구와 맥을 같이하고 있다. 국내연구에서도 Kim \& Back (2017), Mun(2015)의 연구가감성리더십이 지도자 신뢰에 긍 정적인 영향을 미치는 것으로 나타나 본 연구를 지지하고 있다.

감성리더십을 잘 활용하는 지도자일수록 지도자 신뢰가 높 고 선수들의 감성을 잘 이해 및 조절하며, 감성적 정보를 효과 적으로 활용하여 선수들과의 긍정적이고 신뢰적인 관계 형성
을 할 수 있는 것으로 이해된다. 이러한 측면에서 축구지도자 들은 권위적이고 과묵한 지도자 상을 벗어 던지고, 선수들에 게 편안하고 안정된 이미지를 줄 수 있도록 스스로가 노력해 야 하며, 훈련 이외의 시간을 할애하여, 선수들과 대화의 시간 을 많이 가지도록 노력해야 할 것이다. 또한, 카카오톡이나, SNS를 활용하여 선수들과 친숙하게 접근할 필요성이 있다. 선수들을 잘 지도하기 위해서는 선수들과의 신뢰가 먼저이며, 선수들과 소통하기 위해서는 지도자들이 먼저 마음을 열고, 선수들에게 다가가야 할 필요성이 있다.

둘째, 감성리더십은 선수만족에 정적인 인과관계가 있는 것으로 나타났다. 이는 대학축구 지도자들의 감성리더십이 높을수록 선수만족이 높아짐을 의미하며, McCollKennedy \& Anderson(2002)은 조직에서의 정서적 에너지 관리 및 활용은 리더의 책임이며, 리더와 구성원간에 일어나 는 대부분의 상호작용은 감정 에너지 교환으로 다양한 상황에 따라 노출되어 구성원들의 태도와 행동에 영향을 준다고 하여 본 연구를 간접적으로 지지하고 있으며, Gabriel Yiannis \& Griffiths Dorothy(2002)는 리더와 구성원들의 상호작용이 이성적 요인보다는 감성적 요소에 영향을 많이 주는 것으로 나타났으며, 이러한 감성은 조직성과에 긍정적인 영향을 미 친다는 연구 결과가 본 연구와 부분적으로 일치하였다. 또한, 감성리더십 이외의 지도자 리더십과 선수들의 만족간에 관련 성이 있다는 선행연구(Horne \& Carron, 1985; Riemer \& Cheladurai, 1995; Riemer \& Toon, 2001)가 본 연구를 부분적으로 지지해 주고 있다.

대학 축구 지도자들의 리더십 평가에 있어서 팀의 목표 달 성도 중요하지만, 선수들의 만족 여부도 리더십 평가의 주요 한 요인이다. 결국, 지도자들의 리더십 평가는 선수들에 의해 결정된다는 측면을 고려해 볼 때, 지도자들이 팀의 성과를 승. 패 여부에 집착하기보다는 선수들의 만족과 행복에 초점을 맞 췄으면 한다. 감성리더십은 지도자들에게 결과보다는 과정 지향적으로 선수들의 마음을 이해하고 공감하는 능력을 보유 하고 있는지를 선수들에게 평가하도록 하고 있어서 지도자들 의 감성능력을 높일 수 있도록 지도자들은 변해야 한다. 지도 자들이 선수들에게 먼저 다가서서 선수들의 마음을 이해하고 공감할 때, 선수들이 변하고, 팀이 변화될 수 있을 것이다.

셋째, 지도자 신뢰는 선수 만족과 정적인 인과관계가 있는 것으로 나타났다. 지도자 신뢰가 높을수록 선수 만족이 높아 지는 것으로 이러한 결과는 Mulki, Jararnillo \& Locander(2006)의 연구에서 회사원들의 상사에 대한 신뢰 
와 직무 만족과의 관련성이 높다하여 본 연구를 지지하고 있 다. 또한, Brashea, Boles, Belienge \& Brooks(2003), Cunnigham \& MacGreger(2000)의 연구에서 신뢰와 구성 원들의 직무만족도, 결석률, 이직의도에 긍정적인 영향을 미 친다고 하여 본 연구와 부분적으로 일치하며, 직무만족 간에 인과관계를 입증한 연구가 본 연구와 유사점을 보이고 있다. 국내연구에서도, 대학 스포츠 선수들의 지도자 신뢰와 선수 만족을 연구한 선행연구(Kang \& Oh, 2015; Kim, 2011; $\mathrm{Ha}, 2020)$ 가 본 연구와 일치하는 결과를 나타내었다. 하지 만, 골프선수들을 대상으로 연구한 Choi(2013)의 연구에서 지도자 신뢰와 선수만족간의 관련성이 없다는 결과로 본 연구 와 차이점을 보였다. 훈련 상황이나 시합 상황에서 지도자의 능력이 뛰어나고, 훈련 프로그램이 좋다 할지라도 선수와 지 도자간의 믿음과 신뢰가 없거나 낮을 경우, 선수만족은 낮아 질 수밖에 없으며, 경기성과에도 부정적인 영향을 미칠 수 있 다. 이에 현장의 지도자들은 지적인 성숙과 각자의 개성이 독 특한 대학선수들을 이해하고 공감하며, 선수들과의 신뢰를 높이기 위한 노력이 요구된다.

마지막으로 지도자 신뢰는 감성리더십과 선수 만족간의 관 계를 매개하는 것으로 나타났다. 이는 지도자신뢰의 중요성 을 강조하는 결과로, 감성리더십과 선수만족에서 지도자신뢰 는 두 변인을 연결하는 매개변수로 확인되었다. 이는 Deluga(1994)의 연구에서 상사에 대한 신뢰가 부하의 조직 시민행동과 유의한 관계를 가지고 조직시민행동의 상호교환 관계를 통한 리더 신뢰를 통하여 발생한다고 하여 본 연구를 지지하고 있으며, Podsakoff, Mackenzie, Moorman \& Fetter (1990)의 연구에서는 변혁적 리더십과 조직시민 행동 의 관계에서 리더 신뢰에 의해 매개된다고 하여 본 연구와 부 분적으로 일치한다.

국내연구에서도, Won(2012), Yoon(2014)의 연구에서도 리더십과 운동몰입, 지도효율성에서 지도자 신뢰의 매개효과 를 확인하여 본 연구와 부분적으로 일치한다. 선수만족을 높 이기 위해서는 감성리더십은 반드시 지도자 신뢰라는 매개변 수를 거쳐야 되며, 지도자 신뢰를 높이기 위해서는 지도자들 의 감성적인 노력이 요구된다.

\section{결론 및 제언}

본 연구의 결론은 다음과 같다. 첫째, 감성리더십은 지도
자신뢰를 효율적으로 높일 수 있는 리더십으로 지도자들은 감성적인 노력을 통해 선수들과 소통해야 할 것이다. 둘째, 감성리더십은 선수만족과 인과성이 있으므로 승-패 보다는 선수 만족과 행복에 목표를 둔 팀 운영이 요구된다. 셋째, 지 도자 신뢰가 높을수록 선수 만족이 높아진다. 지도자신뢰를 높이기 위해 감성적인 노력이 요구된다. 마지막으로 감성리 더십 발현은 지도자와 선수간의 믿음과 신뢰가 높아져 선수 만족을 향상시킨다.

본 연구의 제언은 다음과 같다. 첫째, 대학축구선수 이외 의 학년별(초·중·고교), 성별(남, 여)에 따른 감성리더십의 비 교 및 영향력 분석할 필요성이 있다. 둘째, 감성리더십의 향 상시킬 수 있는 프로그램을 개발하여, 축구지도자 교육프로 그램에 포함시켜 그 효과를 검증해 볼 필요성이 있다. 셋째, 감성리더십에 대한 경기력과 관련성을 검증하기 위해서 객관 적인 변인(팀 성적, 승률)을 활용하여 분석할 필요성이 있다.

\section{참고문헌}

Bennis, W. (1995). Visionary leadership. San Francisco: Jossey-Bass.

Boss, R. W.(1978). Trust and managerial problem solving revisited. Group and Organization Studies, 3: 31 342.

Brashear, T. G., Boles, J. S., Bellenger, D. N., \& Brooks, C. M. (2003). An Empirical test of trust-building processes and outcomes in sales manager salesperson relationships. Journal of the Academy of Marketing Science ,31(2), 189-200.

Cherniss, C., \& Adler, M. (2000), Promoting Emotional Intelligence in Organizations. Alexandria, VA, American Society for Training and Development.

Cho, C. K., Park, S. H., \& Kim, P. S. (2018). An Effect of University Taekwondo Instructor's Emotional Leadership on Empowerment and Self-management Behavior, The Journal of Humanities and Social science, 9(2), 401-410.

Choi, J. H. (2013). Effects of Mentor Competence and Mentor Function on Self-efficacy, Trust and Players Satisfaction of the Golf Player. Unpublished doctorate's thesis. Konkuk University.

Choi, K. Y., Jeon, S. H., \& Jung, H. T. (2017). Relationship between Coach-Athlete relation and Exercise Volition to Emotional Leadership of Judo Coaches, The Korean 
Journal of Sport, 15(2), 835-845.

Choi, Y. L., Won, Y. S., \& Lee, K. H. (2006). The Effect of Coach's Leadership Style on Trust and Coaching Effectiveness in School Athletic Team. Korean Society for the Sociology of Sport, 19(1), 19-34.

Cooper, R. K., \& Stwaf, A. (1997), Executive EQ: Emotional Intelligence in Leadership and Organizations, New York, Grosset/Putnam.

Crino, M. D., \& White, M. C. (1981). Satisfaction in communication: An examination of the Downs-Hazen measure. Psychological Reports, 49(3), 831-838.

Crosan, M., Vera, D., \& Nanjad, L. (2008). Transcendent leadership: Strategic leadership in dynamic environments. The Leadership Quarterly, 19, 569 - 581.

Cunnigham, J., \& MacGreger, J. (2000). Trust and the design of world complementary constructs in satisfaction and performance. Human Relations, 53, 1575-1591.

Gabriel, Yiannis., \& Griffiths, Dorothy S. (2002). Emotion, Learning and Organizing, The Learning Organization. 9(5). pp. 214-221.

George, J, M. (2000). Emotional and leadership: The role of emotional intelligence. Human Relations, 53, 1.27-1055.

Goleman, D., (1995). Emotional Intelligence. Bantam Books. New York.

Goleman, D., Boyatzis, R., \& McKee, A.(2002). The New Leaders. London: Little Brown.

Cook, J., \& Wall, T. (1980). New work attitude measures of trust, organizational commitment and personal need non-fulfilment. Journal of Occupational Psychology, 53(1), $39-52$.

Deluga R. J.(1994), "Supervisor trust building leader-member exchange and organizational citizenship behavior," Journal of Occupational and Organizational Psychology, 67, 315-326.

Dirks, K. T., \& Ferrin, D. L.(2002), Trust in leadership: Meta-analytic findings and implications for research and practice. Journal of applied psychology, 87(4), 611.

Do, K. M., \& YOU, K. W. (2020). Effects of Emotional Leadership of Middle School Soccer Coaches on Group Cohesiveness. The Korean Journal of Sport, 18(3), 1329-1338.

Dulewicz, V., \& Higgs, M. J. (2003), Design of a new instrument to assess leadership dimensions and styles. Henley Working Paper 0311, Henley Management College, Henley, available at: www:henleymc.ac.uk.

Ha, E, J., \& Kim, Y. S. (2017). The relationship among coaches' emotional leadership, intrinsic motivation, and athletic satisfaction perceived by professional female basketball athletes in korea and japan. Korean Journal of Sport Science, 28(4), 1034-1045.

Ha, J. H. (2020). The Structural Relationship among Coach Trust, Athlete Satisfaction, Knowledge Sharing, and Innovative Behavior Toward College Athletes. The Korean Journal of Sport, 18(1), 551-561.

Horne, T., \& Carron, A. V. (1985). Compatibility in coach athlete relationships. Journal of Sport Psychology, 7(2), 137 -149 .

Jeon, H. S. (2016). The Conceptualization of Athletes'Trust and the Scale Development. Unpublished doctorate's thesis. Seoul National University.

Johnson, G. C., \& Swap, W. C.(1982), Measurement of Specific Interpersonal Trust. Construction and Validation of a Scale to Social Psychology, 43(6), 1306-1317.

Kang, K. H., \& Oh, K. R. (2015). The effects on team cohesion and satisfaction of university athletes by trust in leadership. The Korean Journal of Sports Science, 24(6), 513-525.

Kim, B. (2012). Relationship among Emotional Leadership of Elite Athlete Coach, Athletes' Emotions, Team Climate and Team Effectiveness. The Korean Journal of Sports Science, 21(3), 75-89.

Kim, B. K., \& Lee, T. H. (2019). The Relationship between University Ssireum Coach's Emotional Leadership, Players' Burn-out and Drop Out Intention. The Korean Journal of Sports Science, 28(6), 135-144.

Kim, H. R., \& Kim, Y. H. (2020). Relationship between the Ethical Leadership of Kumdo Instructors, Trust of Instructors and Performance. The Korean Journal of Sport, 18(3), 1359-1367.

Kim, J. H., Wang, C. M., \& Kim, H. D. (2016). The Effects of Competing Values Leadership on Leader Trust and Performance Strategy of Semi-pro Taekwondo Players. Journal of Wellness, 11(3), 369-384.

Kim, J. W., \& Kim, J. N. (2002). Transformational Sport 
Leadership on Athletic's Trust, Identification with Leader, and Sport Behaviors. Korean Society of Sport Psychology, 13(2), 43-64.

Kim, S. (2014). An Exploration of the Causal Relationship among Transactional Leadership, Coaches' Emotional Intelligence, and Athlete Satisfaction in Soccer Teams. The Korea Contents Society, 14(9), 450-462.

Kim, S. I. (2011). The Relationship Among the Trust in Leader, Athletic Satisfaction and Athletics Outcomes of Football Players. International Journal of Coaching Science, 13(4), 79-87.

Kim, S. W., \& Back, Y. S. (2017). The Effects of Emotional Leadership on Trust in Leader and Organizational Commitment. Ordo Economics Journal, 20(1), 91-109.

Kim, T. I., \& Back, N. S. (2016). The effect of Emotional Leadership on Leader Trust and Leader-Member Exchange in Taekwondo Coach. The Korean Journal of Sport, 14(4), 219-230.

Kim, Y. K. (2012). Relationship Among Taekwondo Leader's Emotional Leadership, Team Climate, Athlete Satisfaction and Team Performance. Korean Journal of Sport Studies, 51(6), 295-305.

Lee, J. B. \& Cho, L. H. (2009). The Relationship Among Charismatic Leadership, Trust in Leader, and Instructing Effectiveness of Taekwondo Instructor, The Journal of Korean Alliance of Martial Arts, 11(2), 221-233.

Lee, M. S. (2011). Effects of coach confidence on athlete satisfaction and perceived performance in throwers. Journal of Korea Academia-Industrial cooperation Society, 12(9), 4054-4060.

Lee, N. Y., \& Jun, S. H. (2016). Effects of Leader's Leadership Behavior Type on Elementary School Football Players' Trust in Leader and Intention to Exercise Adherence -Focusing on the Mediating Effects of 'Trust in Leader', Korean Society For Early Childhood Physical Education, 17(1), 63-72.

Lee, S. H., \& Oh, B. K. (2012). The Effect of Ssirum Coaches' Transformational Leadership on Trust and Player Satisfaction, Journal of Sport and Leisure Studies, 47(1), 57-67.

Lim, H. J., \& Kim, Y. K. (2011). Relationship between Cycle Leader's Emotional Leadership, Athlete Satisfaction and
Team Performance, Journal of Sport and Leisure Studies, 45, 161-172.

Mayer, J. D., DiPaolo, M., \& Salovey, P.(1990). Perceiving affective content in ambiguous visual stimuli: A component of emotional intelligence. Journal of Personality Assesment, 54(3-4), 72-781.

McColl-Kennedy J, R., \& Anderson R, D. (2002). Impact of leadership style and emotion on subordinate performance, The Leadership Quarterly, 13(5), 545-559.

Mulki, J. P., Jaramillo, F., \& Locander, W. B. (2006). Effects of ethical climate and supervisory trust on salesperson's attitudes and intentions to quit. Journal of Personal Selling and Sales Management, 26(1),19-26.

Mun, K. S. (2015). Structural relationships of The Emotional Leadership, Leaders trust, Sports confidence and Exercise commitment of Taekwondo Leaders. Unpublished doctorate's thesis. Kyunghee University.

Park, G. B., \& Jung, K. G. (2020). Effect of Soccer Coach's Emotional Leadership on Soccer Players' Self-Esteem and Exercise Adherence. Journal of Coaching Development, 22(1), 67-78.

Podsakoff, P. M., S. B. Mackenzie, R. H. Moorman and R. Fetter(1990). "Transformational leader behaviors and their effects on follower's trust in leader, satisfaction and organizational citizenship behavior," Leadership Quarterly, 1, 107-142.

Riemer, H. A., \& Chelladurai, P. (1995). Leadership and satisfaction in athletics. Journal of Sport and Exercise Psychology, 17(3), 276-293.

Riemer, H. A., \& Ton, K. (2001). Leadership and satisfaction in tennis: Examination of congruence, gender, and ability. Research Quarterly for Exercise and Sport, 72(3), 243-256.

Salovey, P., \& Mayer, J. D.(190). Emotional intelligence. Imagination. Cognition and Personality, 9(3), 185-21.

Taylor, S. N. (2010). Redefining leader self-awareness by integrating the second component of self-awareness. Journal of Leadership Studies, 3(4), 57-68.

Tyler, T. R., \& Degoey, P. (1996). Trust in organizational authorities: The influence of motive attributions on willingness to accept decisions. In R. M. Kramer \& T. R. Tyler (Eds.), Trust in organizations: Frontiers of theory and research (p. 331 -356). Sage Publications, Inc. 
Witt, L. A., \& Ferris, G. R. (2003). Social skill as moderator of the conscientiousness-performance relationship: Convergent results across four studies. Journal of Applied Psychology, 88(5), 809 - 820.

Won, H. J. (2012). The effect of leadership style of America Taekwondo master on master trust, exercise commitment and coaching effectiveness. Unpublished doctorate's thesis. Donga University.

Wu, S. Y., \& Turban, D. B.(2009). Social skill in the workplace: What is social skill and what are its sub-skills. In Southern
Management Association 2009 Meeting Proceedings (p. 1-6).

Yoon, Y. J. (2014). The Relation of the Taekwondo Master's Charismatic Leadership on Truth and Exercise Commitment. Unpublished doctorate's thesis. Dongguk University.

You, K. W. (2020). The Relationship between High School Coach's Servant Leadership, Empowerment, and Athlete Satisfaction. The Korean Journal of Sport, 18(1), 531-539.

Yukl, G. (2002). Leadership in Organizations: Fifth Edition. New Jersey: Prentice-Hal Inc. 


\section{대학 축구 선수들이 인지하는 감성리더십, 지도자신뢰, 선수 만족과의 관계 \\ 김성훈 ${ }^{1}$ 신정택 ${ }^{2}$ \\ ${ }^{1}$ 연세대학교 연구원 \\ 동의대학교 교수}

[목적] 본 연구의 목적은 대학 축구 지도자의 감성 리더십, 지도자 신뢰, 선수 만족과의 관계를 분석하는 것이다. [방법] 대학축구 선수 288명을 대상으로 편의표본 추출을 통해 감성리더십 질문지, 지도자 신뢰 질문 지, 선수만족 질문지를 설문하였다. 본 연구의 목적 달성을 위해 SPSS 23.0과 AMOS 23.0을 사용하여 빈도분 석, 확인적 요인분석, 신뢰도 검증 및 상관관계 분석을 실시하였으며, 구조방정식 모형을 검증하여 결론을 도 출하였다. [결과] 첫째, 감성 리더십은 지도자 신뢰에 정적인 영향을 미치는 것으로 나타났다. 둘째, 감성리더 십은 선수 만족에 정적인 영향을 미치는 것으로 나타났다. 셋째, 지도자 신뢰는 선수 만족에 정적인 영향을 미치는 것으로 나타났다. 마지막으로 지도자 신뢰는 감성 리더십과 선수 만족과의 관계를 매개하는 것으로 나타났다. [결론] 감성 리더십은 지도자 신뢰를 효율적으로 높일 수 있는 리더십으로 지도자들은 감성적인 노력을 통해 선수들과 소통해야 하며, 승-패 보다는 선수 만족과 행복에 목적을 둔 팀 운영이 요구된다.

주요어: 감성리더십, 지도자 신뢰, 선수만족, 매개효과, 대학축구선수 